\title{
Effects of Ankle Joint Position during Closed Kinetic Chain Exercise on Strength and Balance in Chronic Stroke
}

\author{
Ye-Eun Kim', Dae-Hyouk Bang², Won-Seob Shin ${ }^{3}$ \\ 'Department of Physical Therapy, Graduate School of Health and Medicine, Daejeon University; ${ }^{2}$ Department of Physical Therapy, Graduate School \\ of Daejeon University; ${ }^{3}$ Department of Physical Therapy, College of Health and Medical Science, Daejeon University, Daejeon, Korea
}

Purpose: This study was conducted to determine the effects of ankle joint position during closed kinetic chain (CKC) exercise on knee extensor strength and balance in patients with chronic stroke.

Methods: Sixteen patients with chronic stroke participated in the study. Participants were randomly assigned to two groups: $15^{\circ}$ ankle joint plantar flexion group $(n=8)$ and ankle joint neutral group $(n=8)$ during CKC exercise. All participants underwent conventional physical therapy for 30 minutes. In addition, the experimental group ( $15^{\circ}$ ankle joint plantar flexion group) and control group (ankle joint neutral group) participated in a 20-minute CKC exercise program. In both groups exercise was performed three times a week for four weeks. Outcomes including knee extensor strength and balance ability (Five times sit-to-stand test, Timed up and go test, and Balancia) were measured before and after exercise.

Results: Significant differences in knee extensor strength and balance ability were observed between pre- and post-exercise in all groups $(p<0.05)$. The improvement of knee extensor strength and dynamic balance was significantly higher in the experimental group than in the control group $(p<0.05)$.

Conclusion: These findings demonstrated that $15^{\circ}$ ankle joint plantar flexion during closed kinetic chain exercise is effective in improvement of knee extensor strength and dynamic balance in patients with chronic stroke.

Keywords: Ankle joint, Closed kinetic chain, Stroke, Strength, Balance

\section{서 론}

뇌졸중은 운동 및 감각장애를 초래하며 일상생활동작에 많은 제한 을 일으키는 중추신경계 질환이다.' 뇌졸중 이후 근력의 약화는 일반 적인 현상이며 근력과 상지기능뿐만 아니라 보행, 균형 잡기, 보호 반 사 반응과 같은 일상생활수행능력과 밀접한 연관이 있다고 보고되 었다. ${ }^{2,3}$ 그러므로 근 활성화 증가를 통한 효율적인 근력강화는 일상 수행능력뿐만 아니라 작업능력과 신체 전반적인 능력을 향상시키는 데 매우 중요한 요소로 작용한다. ${ }^{4}$ 뇌졸중으로 인한 편마비 환자의 대부분은 정적인 기립자세 동안 마비 측 하지에는 $25-45 \%$ 정도의 체 중지지만 이루어지며, ${ }^{5}$ 이로 인해 비대칭적인 신체정렬과 부적절한 체중이동이 발생한다. ${ }^{6}$ 이러한 현상은 뇌졸중 환자의 기능적 동작 수 행 시 균형과 관련된 문제로 신체의 각 부분에서 보상 움직임이 나타 나게 되어 정상인보다 더 많은 에너지를 소모하게 되고, ${ }^{7}$ 이로 인해
일상생활을 위한 지속적인 동작 수행을 어렵게 만든다. ${ }^{8}$ 따라서, 뇌졸 중 환자의 수행능력의 향상과 사회참여를 위해 균형능력의 향상은 반드시 필요하다.

뇌졸중 환자의 하지 근력을 증진시키는 방법에는 저항에 따라 운 동학적 방법으로 닫힌 사슬과 열린 사슬 운동으로 분류할 수 있다. 닫힌 사슬 운동은 손이나 발이 지면에 고정되어 있는 상태에서 체중 을 이용하여 운동을 수행하는 것으로 관절의 안정성에 영향을 주는 길항근을 강화시키며, 열린 사슬 운동은 체중이 부하되지 않고 손이 나 발이 자유롭게 움직이는 상태에서 팔굽관절이나 무릎관절의 움 직임을 유발하는 운동으로 근육의 모양과 근력을 유지하는 것을 목 적으로 사용한다. ${ }^{10}$ 닫힌 사슬과 열린 사슬 운동의 효과 차이를 알아 보고자 여러 선행 연구들이 이루어졌는데, 닫힌 사슬운동 방법이 열 린 사슬 운동방법보다 근력 증가에 더욱 효과적이라고 보고하였다. ${ }^{10}$ 만성 뇌졸중 환자를 대상으로 닫힌 사슬 운동 방법 중의 하나인 스 
쿼트(squat)를 수행할 때 $45^{\circ}$ 에서 $60^{\circ}$ 사이의 무릎관절 각도에서 넙다 리네갈래근과 뒤넙다리근의 동시수축 유발이 가장 효과적으로 나타 났으며, 안쪽넓은근의 선택적인 수축을 촉진할 수 있다. ${ }^{11}$ 또한 발목 관절 박바닥쪽굽힘 후 닫힌 사슬 운동시 가쪽넓은근과 장딴지근이 활성화되었다. 발목 근력의 약화는 뇌졸중 환자의 기능적 향상을 제 한하는 요소이며, 무릎 관절의 펴는 힘 증가와 밀접한 연관성을 가지 므로 기능의 향상을 위해 발목의 근력 강화운동이 필요하다.12

초기 뇌졸중 환자를 대상으로 열린 사슬 운동과 닫힌 사슬 운동 을 시행한 연구에서 하지의 근력증진과 균형능력 향상에 효과적이라 고 하였으며, ${ }^{13}$ 뇌졸중 환자에게 지지면에 따른 닫힌 사슬 운동을 실 시하였을 때 근력, 균형능력, 대칭적 체중지지 등이 향상되었음은 검 증되었다. ${ }^{4}$ 하지만, 발목관절 위치에 따른 닫힌 사슬 운동이 편마비 환자의 근력, 균형능력에 미치는 영향에 대한 연구는 부족하다. 또한, 선행 연구에서 발목 근력의 강화에 대한 중요성은 강조하였지만, 발 목각도에 따른 근력 향상의 차이를 조사하지 않았다. 따라서 본 연구 는 뇌졸중 환자가 닫힌 사슬 운동이면서 등척성 수축인 스퀴트 동작 시 발목관절의 위치를 다르게 하여 훈련하였을 때, 근력과 균형능력 에 어떠한 영향을 주는지 확인하고 뇌졸중환자의 기능적인 기능향 상을 위해 더욱 효과적인 방법을 제시하고자 한다.

\section{연구방법}

\section{1. 연구대상}

본 연구는 대전소재 B 병원에 입원하여 물리치료를 받고 있는 뇌졸
중으로 인한 편마비 환자 중 발병 후 6 개월 이상 지난 자 16 명을 대상 으로 하였다. 대상자들은 닫힌 사슬 운동을 수행하는 발목위치에 따 라 제비뽑기를 통한 무작위 선별로 발목관절 $15^{\circ}$ 발바닥쪽굽힘 위치 에서의 닫힌 사슬 운동군 8 명과 발목관절 중립 위치에서의 닫힌 사 슬 운동군 8 명으로 배정되어 중재를 완전히 수행하였으며, 대전대학 교 연구윤리심의위원회에 심의를 받았다.

연구대상자의 선정 기준은 다음과 같다. 30 초 이상 독립적으로 기 립 자세 유지가 가능 하며, 뇌졸중 이외의 다른 신경학적 문제나 정형 외과적 손상이 없고, 의사소통과 연구자의 지시에 적절하게 따를 수 있는 사람으로 연구 참여에 관한 충분한 설명을 듣고 연구 참여에 동 의한 대상자를 선정하였으며, 실험 절차는 다음과 같다(Figure 1).

\section{2. 측정 도구}

1) 동적균형검사

(1) 5 회 반복 앉고 일어서기 검사(Five times sit-to-stand test, FTSST) 팔걸이가 없는 $43 \mathrm{~cm}$ 높이의 의자에서 대상자가 비마비측팔로 마비 측 팔을 잡게 한 후 최대한 빠른 속도로 앉고 일어서기를 5 회 반복 수 행하는데 소요되는 시간을 측정하여 기록한다. 측정자 간 신뢰도는 $\mathrm{ICC}=0.89$ 이다. ${ }^{5}$ 검사는 총 3 회 측정하여 평균값을 구하였다.

(2) 일어나 걸어가기 검사(Time up and go test, TUG) 일어나 걸어가기 검사는 팔걸이가 있는 $50 \mathrm{~cm}$ 높이의 의자에서 일어 나 $3 \mathrm{~m}$ 를 걸어간 뒤 표시해 둔 부분에서 다시 돌아와 의자에 앉는 동 작을 수행하는 동안 소요된 시간을 기록한다. 검사는 총 3 회 반복 수

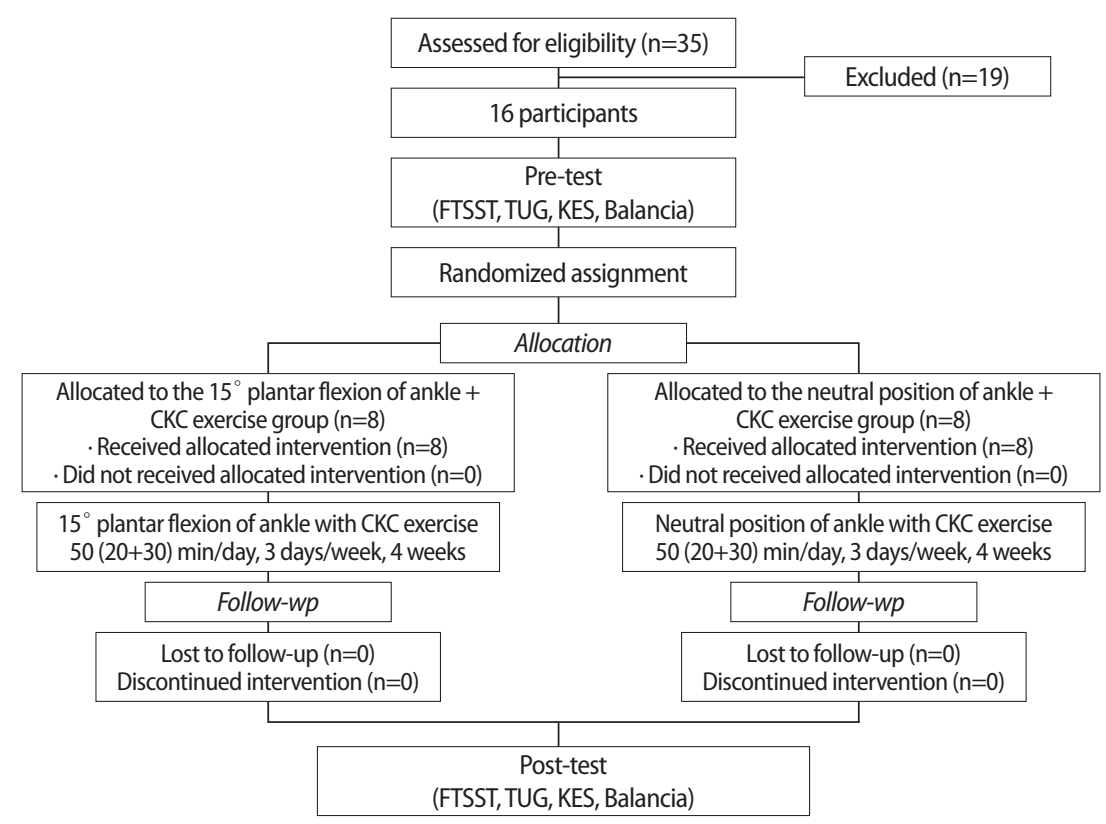

Figure 1. Flow Diagram of the study.

CKC: Closed kinetic chain, FTSST: Five times sit-to-stand test, TUG: Timed up and go test, KES: Knee extensor strength. 
행하여 측정한 값의 평균을 구하였다. 이 검사에 대한 검사자 내 신뢰 도는 0.98 , 검사자 간 신뢰도는 0.99 로 높은 신뢰도를 보였다. ${ }^{16}$

\section{2) 근력검사(knee extensor strength, KES)}

무릎 폄근의 근력을 평가하기 위해 검사자는 대상자가 높낮이 조절 이 가능한 검사침대에 무릎을 $90^{\circ}$ 굽힘하고 앉도록 한 다음 무릎을 펴도록 하고 양쪽 복사뼈 선 근위부에 근력측정계를 이용해 정적인 힘으로 저항을 주어 무릎폄근의 근력을 측정한다. ${ }^{17}$ 무릎폄근의 근력 은 3 번 측정한 값의 평균을 구하였다. 이 검사에 대한 검사자내 신뢰 도는 ICC 0.86-0.94로 높은 신뢰도를 보였다.18

\section{3) 정적균형검사}

본 연구는 대상자의 정적 균형능력을 평가하기 위해 $\mathrm{Wii}$ 균형판(Wii balance board, Nintendo, Japan)을 사용하여 측정하였다. 수집된 자료 는 Balancia 프로그램(Balancia 2.0, Mintosys, Seoul, Korea)을 사용하여 기립자세 시 양 하지의 체중분포와 압력중심(center of pressure)의 동 요거리와 동요속도를 분석하였다. 검사는 총 3 회를 측정하여 평균값 을 계산하였으며, 각 측정 사이의 휴식시간은 1 분으로 하였다. Wii 균 형판의 검사-재검사의 신뢰도는 ICC 0.66-0.94이며, ${ }^{19}$ Balancia 프로그 램의 동요거리와 동요속도에 대한 검사-재검사의 검사자 내 신뢰도 는 ICC 0.79-0.94로 높은 신뢰도를 보였다. ${ }^{20}$

\section{3. 중재방법}

본 연구의 모든 대상자는 작업치료, 기능적 전기자극치료, 매트운동 및 보행훈련 등의 일반적인 물리치료를 하루에 30 분씩, 주 5 회 받았 다. 일반적인 물리치료 후 추가적으로 각 군은 20 분, 주 3 회, 4 주간 닫 힌 사슬 운동을 실시하였다. 실험군은 제작한 경사판에서 발목관절 을 $15^{\circ}$ 발바닥쪽굽힘이 되도록 한 위치에서 시행하였으며, 대조군은 발목관절 중립위치에서 시행하였다.

닫힌 사슬 운동 동안 두 군의 무릎관절은 각 측정기(goniometer)를 사용해 $60^{\circ}$ 굽힘이 되도록 하였으며, 대상자는 양발의 간격을 어깨 너 비로 벌리고 팔은 자연스럽게 놓도록 한 자세에서 시작하였다. 닫힌 사슬 운동시 환측으로 체중이동을 위해 선을 그려놓은 거울을 사용 하였고, ${ }^{6}$ 무릎관절 폄근에 2 초간 등척성 수축을 유도한 후 다시 시작 자세로 돌아와 2 초간 휴식을 취하게 하였다. 이와 같은 방법으로 20 분씩 닫힌 사슬 운동을 실시하였다.

\section{4. 분석방법}

본 연구의 실험에서 수집된 모든 자료는 윈도우용 SPSS 18.0 프로그 램을 이용하여 통계적 분석하였다. 연구대상자들의 일반적인 특성은 평균과 표준편차를 구하기 위해 기술통계를 시행하였다. 모든 변수
의 정규성 검정을 위해 Shapiro-Wilk test를 사용하였고 그 결과 정규 분포함을 알 수 있었다. 그룹 내의 중재 전후의 근력, 정적 균형능력과 동적 균형능력의 차이를 비교하기 위해 대응표본 t-검정(paired t-test) 을 시행하였고, 그룹 간 중재방법에 따른 변화량을 비교하기 위하여 독립표본 t-검정(independent t-test)을 사용하였다. 모든 변인에 대한 통계학적 유의수준은 0.05 로 설정하였다.

\section{결 과}

본 연구에 참여한 총 16 명의 대상자들은 모든 실험과정을 마쳤으며, 대상들의 일반적인 특징은 Table 1과 같다. 실험군인 발목관절 $15^{\circ}$ 발 바닥쪽굽힘 닫힌 사슬 운동군은 총 8 명이며, 평균 발병일은 39.3 개월, 평균연령은 56.6 세이다. 대조군인 발목관절 중립위치 닫힌 사슬 운 동군은 총 8 명이며, 평균 발병일은 45.9 개월, 평균연령은 58.5 세이다. 연구대상자의 일반적 특성에 대한 두 그룹 간 유의한 차이는 없었다 ( $\mathrm{p}>0.05)$.

중재 전 두 그룹 간 5 회 반복 앉고 일어서기 검사 $(\mathrm{t}=1.080)$, 일어나 걸어가기 검사 $(\mathrm{t}=-0.269)$, 근력검사 $(\mathrm{t}=0.666)$ 의 사전평가 값은 동질하 였으며, 또한 정적 균형 검사 중 동요 거리 $(\mathrm{t}=0.291)$ 와 동요 속도 $(\mathrm{t}=$ 1.477)의 사전평가 값에서도 그룹 간 차이가 없었다. 중재 후 5 회 반복 앉고 일어서기 검사와 일어나 걸어가기 검사에서 실험군과 대조군 모 두 동적 균형능력에 유의한 변화가 있었으며, 대조군보다 실험군에서 더 효과가 있었다 $(\mathrm{p}<0.05)$. 또한 무릎 신전 근력검사에서도 중재 후 두 군 모두 유의한 증가가 있었으며, 실험군에서 더 효과가 있었다 $(\mathrm{p}<0.05)$. 정적 균형검사 중 동요 거리는 실험군에서만 증가하였다 $(\mathrm{p}<0.05)$. 정적 균형검사 중 동요 속도에서 실험군과 대조군 모두 중

Table 1. Demographic data of the participants

\begin{tabular}{lccc}
\hline & $\begin{array}{c}15^{\circ} \text { plantar } \\
\text { flexion CKC } \\
\text { exercise group } \\
(n=8)\end{array}$ & $\begin{array}{c}\text { Neutral CKC } \\
\text { exercise group } \\
(n=8)\end{array}$ & p-value \\
\hline Gender (n) & 4 & 6 & 0.67 \\
Male & 4 & 2 & \\
Female & 3 & 5 & 0.32 \\
Side of stroke (n) & 5 & 3 & 0.30 \\
Right & 2 & 4 & 0.76 \\
Left & 6 & 4 & 0.92 \\
Type of stroke (n) & $39.3(17.4)$ & $45.9(18.6)$ & 0.52 \\
Infarction & $56.6(6.0)$ & $58.5(6.8)$ & \\
Hemorrhage & $26.3(2.2)$ & $26.8(1.8)$ & \\
Time after stroke (month) & & & \\
Age (year), mean (SD) & & & \\
MMSE (scores), mean (SD) & & & \\
\hline
\end{tabular}

MMSE: Mini-mental state examination. 
Table 2. Descriptive measurements

\begin{tabular}{|c|c|c|c|c|c|c|c|}
\hline \multirow{2}{*}{ Variables } & \multicolumn{3}{|c|}{$\begin{array}{l}15^{\circ} \text { plantar flexion of ankle }+ \\
\text { CKC exercise group }(n=8)\end{array}$} & \multicolumn{3}{|c|}{$\begin{array}{l}\text { Neutral position of ankle }+ \\
\text { CKC exercise group }(n=8)\end{array}$} & \multirow{2}{*}{$\begin{array}{l}\text { Between groups } \\
\text { p-values }(95 \% \mathrm{Cl})\end{array}$} \\
\hline & Pre-test & Post-test & $\begin{array}{l}\text { Within groups } \\
\text { p-values }\end{array}$ & Pre-test & Post-test & $\begin{array}{l}\text { Within groups } \\
\text { p-values }\end{array}$ & \\
\hline FTSST (second) & $18.87(7.08)$ & $11.41(1.67)^{*,+}$ & 0.014 & $15.89(3.27)$ & $13.56(2.09)$ & 0.006 & $0.039(-4.172$ to -0.019$)$ \\
\hline TUG (second) & $24.39(12.47)$ & $13.81(2.39)^{\kappa_{\text {, }}}$ & 0.025 & $25.97(11.05)$ & $22.85(9.47)^{*}$ & 0.004 & $0.020(-16.440$ to -1.6333$)$ \\
\hline KES (Nm) & $70.74(32.82)$ & $112.57(22.36)^{*,+}$ & $<0.001$ & $59.72(33.36)$ & $83.56(24.45)^{*}$ & 0.001 & 0.036 (2.160 to 55.858$)$ \\
\hline \multicolumn{8}{|l|}{ Balancia } \\
\hline Sway distance (mm) & $96.62(21.91)$ & $81.75(14.09)^{*}$ & 0.023 & $104.40(21.03)$ & $87.52(11.75)$ & 0.008 & $0.729(-12.807$ to 16.821$)$ \\
\hline Sway velocity $(\mathrm{mm} / \mathrm{s})$ & $3.69(0.96)$ & $2.73(0.47)^{*}$ & 0.014 & $4.57(0.98)$ & $2.92(0.14)^{*}$ & 0.003 & 0.162 (-0.311 to 1.690$)$ \\
\hline
\end{tabular}

CKC: Closed kinetic chain, FTSST: Five times sit-to-stand test, TUG: Timed up and go test, KES: Knee extensor strength.

*Significant difference within groups $(p<0.05)$, 'Significant difference between groups $(p<0.05)$.

재 후 증가가 있었으나 $(\mathrm{p}<0.05)$, 실험군과 대조군 사이에는 유의한 차 이가 없었다 $(\mathrm{p}>0.05)$ (Table 2$)$.

\section{고 찰}

뇌졸중 환자의 근력과 균형능력의 향상은 일상생활수행능력과 밀접 한 관련이 있기 때문에 뇌졸중환자의 재활에 있어 매우 중요한 요소 로 고려되어야 한다. ${ }^{14}$ 임상에서 하지의 근력 증가를 위해 주로 사용 되어 지고 있는 닫힌 사슬 운동은 근 활성화를 통한 근력의 증가에 매우 효과적인 방법으로 알려져 있다. 본 연구는 닫힌 사슬 운동시 발목관절의 중립위치와 $15^{\circ}$ 발바닥쪽굽힘에 따른 근력과 균형의 변 화를 알아보고자 하였다. 그 결과 발목관절 $15^{\circ}$ 발바닥쪽굽힘 닫힌 사슬 운동군이 대조군에 비해 근력, 동적 균형능력에서 유의한 차이 를 보였다 $(\mathrm{p}<0.05)$.

본 연구에서는 하지의 근육 중 무릎 폄근의 근력강화 훈련을 발목 관절 위치에 변화를 주어 실험을 진행하였다. 무릎 폄근은 기능적인 동작 수행 시 동적 안정성에서 중요한 요소이며, 무릎 폄근의 근력과 균형과의 상관성에서 근력강화운동을 강조하였다. ${ }^{21-23}$ 본 연구에서 두 그룹 모두 무릎 폄근 근력의 유의한 증가가 있었으며, 대조군과 비 교해 실험군에서 유의한 증가가 있었다 $(\mathrm{p}<0.05)$. 체중지지 운동시에 발목관절 중립위치 닫힌 사슬 운동보다 $15^{\circ}$ 발바닥쪽굽힘 닫힌 사슬 운동이 무릎 폄근의 근력강화에 더 효과적이라는 것을 제시한다. 이 러한 결과는 스쿼트 운동 시에 지면의 기울기 변화는 안정성과 하지 근육 활동에 영향을 줄 수 있으며, 뇌졸중 환자를 대상으로 발목관 절을 발바닥쪽굽힘한 후 스쿼트 운동을 실시하였을 때 전반적인 하 지 근력이 향상되는 데 좀 더 효과적이라는 선행연구와 일치한다. ${ }^{6}$

닫힌 사슬 운동은 원심성 수축을 통하여 근수축의 동적 안정성에 기여하며, 관절을 압박하는 전단력(shear force)으로 인한 압박변화에 의해 기계적 수용기가 자극되고, 고유수용성감각의 촉진과 관절의 안정성을 증가시킴으로써 동적 균형조절 능력과 근력을 향상시키는
운동방법이다. ${ }^{24}$ 또한 뇌졸중 환자의 근력과 균형의 상관관계를 알아 본 선행연구에서 근력의 향상이 동적 균형평가인 안정성한계와 유의 한 상관관계를 보인다는 결과가 나타났으며, ${ }^{25}$ 이러한 결과는 본 연구 에서 근력과 동적 균형능력의 향상과 일치하는 결과이다.

뇌졸중 환자에게 발목 근력의 약화는 균형과 기능적 활동의 저하 에 영향을 주기 때문에 뇌졸중 후 관절 가동범위 증진 및 발목관절 의 근력 강화를 위한 운동을 통하여 근력과 균형능력을 증진시켜야 한다. ${ }^{13} \mathrm{Lee}^{12}$ 는 발목관절 발바닥쪽굽힘 강화 훈련을 통해 무릎 관절 의 펴는 힘이 증가되고, 이러한 하지의 근력증가는 균형능력 증가와 밀접한 관련성을 보인다고 하였으며, $\mathrm{Kim}^{26}$ 은 넙다리네갈래근, 앞정 강이근, 장딴지근은 기립자세와 자세 안정성유지에 주요한 영향을 미치는 근육으로서 균형 능력 향상에 중요하다고 하였다. 또 다른 선 행연구에서는 편평한 지면보다 발목관절이 발바닥쪽굽힘 된 지면에 서 스쿼트(squat)를 적용하는 것이 전반적인 하지 근력을 증가시키는 데 더 효과적이라 제시하면서 뇌졸중 환자에게 발목관절을 $20^{\circ}$ 이상 발바닥쪽굽힘 후 폄근 훈련을 하는 것은 적절하지 않다고 하였다. ${ }^{27}$ 또한 스쿼트(squat)를 하는 동안 지면의 경사변화는 하지의 근육활동 과 안정성에 영향을 줄 수 있다고 하였으며, 안쪽넓은근과 가쪽장딴 지근은 발목관절을 $15^{\circ}$ 발바닥쪽굽힘한 상태에서 무릎을 $45^{\circ}$ 로 굽힘 시켜 스쿼트를 수행할 때 더 촉진된다고 하였다.612 이에 본 연구는 닫 힌 사슬 운동시 발목관절 $15^{\circ}$ 발바닥쪽굽힘과 중립위치로 구분하여 각각의 운동 방법을 적용하였을 때 뇌졸중 환자의 무릎 폄근의 근력 뿐만 아니라 정적, 동적 균형에 어떠한 영향을 미치는지를 알아보고 자 하였으며 뇌졸중 환자의 임상 치료에 있어 좀 더 효과적인 방법을 제시하고자하였다.

정적 균형에서는 군 간 유의한 차이를 보이지 않았으나( $\mathrm{p}>0.05)$, 운동군의 동요 거리와 동요 속도에서 중재 후 유의한 증가가 있었으 며, 대조군의 동요 속도에 유의한 차이가 있었다 $(\mathrm{p}<0.05)$. 이러한 결 과는 건강한 성인에게 열린 사슬 운동과 닫힌 사슬 운동을 실시 하 였을 때 운동 전과 비교하여 동적 균형 능력 향상이 유의하게 증가하 
였다는 선행 연구의 결과와 일치한 결과이며, ${ }^{24}$ 이는 중재운동을 통 해 고유수용성 감각 입력을 증대시키고 경직을 감소시켜 뇌졸중 환 자의 균형이 개선되었다. ${ }^{9}$ 하지만 본 연구에서 발의 위치에 대한 그룹 간의 차이가 없었으므로 발의 위치에 대한 정적 균형에는 영향을 미 치지 않음을 알 수 있었다.

본 연구의 제한점은 만성 뇌졸중 환자를 대상으로 적은 대상자의 수와 단기간의 중재로 연구결과를 모든 뇌졸중환자들에 대해 보편 화시키기는 힘들다. 또한 연구의 중재에 사용되었던 닫힌 사슬운동 의 장비로 동일하게 보편화하여 적용하는 것은 제한적일 수 있다. 하 지만 닫힌 사슬 운동에 대한 개념을 이해하고 대상자에게 적절한 중 재를 적용한다면 운동의 효과를 얻을 수 있을 것이다. 향후 연구에서 는 뇌졸중환자에게 다양한 중재방법의 닫힌 사슬 운동을 고려하여 효과적인 재활이 이루어져야 할 것이다.

본 연구는 뇌졸중 환자가 닫힌 사슬 운동이면서 등척성 수축인 스 쿼트(squat) 동작 시 발목관절의 위치를 다르게 하여 훈련하였을 때, 근력과 균형능력에 미치는 영향을 비교하기 위해 시행하였다. 본 연 구의 결과 뇌졸중 환자의 근력과 동적 균형능력의 향상을 위하여 닫 힌 사슬 운동의 효과를 지지하는 것이며, 발목관절 발바닥쪽굽힘의 임상적용 가능성을 제시해주는 것이다. 이러한 결과는 닫힌 사슬 운 동시 발목관절 $15^{\circ}$ 발바닥쪽굽힘이 무릎 폄근의 근력과 동적 균형능 력을 향상시키는데 도움이 된다는 것을 의미한다. 같은 기간 동안에 더 효과적인 방법을 적용함으로써 기능 향상의 극대화를 이룰 수 있 을 것이다. 이는 뇌졸중 환자의 일상생활수행능력의 향상과 사회참 여의 기회를 줄수 있는 효과적인 훈련 방법이 될 수 있을 것이다.

\section{REFERENCES}

1. Farqalit R, Shahnawaz A. Effect of foot position during sit-to-stand training on balance and upright mobility in patients with chronic stroke. Hong Kong Physiotherapy Journal. 2013;31(2):75-80.

2. Flansbjer UB, Downham D, Lexell J. Knee muscle strength, gait performance, and perceived participation after stroke. Arch Phys Med Rehabil. 2006;87(7):974-80.

3. Kim BY, Choi WH. The effects of interferential current therapy on spasticity, range of motion, and balance ability in stroke patient. J Kor Phys Ther. 2013;25(4):187-94.

4. Flansbjer UB, Miller M, Downham D et al. Progressive resistance training after stroke: Effects on muscle strength, muscle tone, gait performance and perceived participation. J Rehabil Med. 2008;40(1):42-8.

5. Son SM. Effects of constrained-weight shifting train on postural balance and gait parameter and muscle activation of patients with hemiplegia in standing posture. Daegu University. Dissertation of Doctorate Degree. 2014.

6. Ki KI, Choi JD, Cho HS. The effect of ground tilt on the lower extremity muscle activity of stroke patients performing squat exercises. J Phys Ther
Sci. 2014;26(7):965

7. Bang DH, Shin WS, Kim SY et al. The effects of action observational training on walking ability in chronic stroke patients: A double-blind randomized controlled trial. Clin Rehabil. 2013;27(12):1118-25.

8. Choi KW. Effects of progressive task-oriented resistive training on lower extremity strength, balance and gait in stroke. Sahmyook University. Dissertation of Master's Degree. 2010.

9. Lee NK. The effects of closed and open kinetic chain exercises on lower limb muscle activity, balance and gait in stroke patients. Daegu University. Dissertation of Master's Degree. 2011.

10. Lee KY, Shin WS. The effects of closed kinetic and open kinetic chain exercises using knee reposition sense in chronic stroke patients. J Kor Phys Ther. 2014;26(3):182-90.

11. Tang SF, Chen CK, Hsu R et al. Vastus medialis obliquus and vastus lateralis activity in open and closed kinetic chain exercises in patients with patellofemoral pain syndrome: An electromyographic study. Arch Phys Med Rehabil. 2001;82(10):1441-5.

12. Lee JH. A study isokinetic strength characteristics of low extremity extensors according to ankle joint position in stroke patients. Catholic University of Daegu. Dissertation of Master's Degree. 2014.

13. Kwon OK, Shin WS. Effects of closed and open kinetic chain exercises on knee extensor strength and balance in patients with early stroke. J Korean Soc Phys Med. 2014;9(2):223-31.

14. Bang DH, Shin WS, Noh HJ et al. Effect of unstable surface training on walking ability in stroke patients. J Phys Ther Sci. 2014;26(11):1689-91.

15. Lord SR, Murray SM, Chapman K et al. Sit-to-stand performance depends on sensation, speed, balance, and psychological status in addition to strength in older people. J Gerontol A Biol Sci Med Sci. 2002;57(8): 539-43.

16. Mehrholz J, Wagner K, Rutte K et al. Predictive validity and responsiveness of the functional ambulation category in hemiparetic patients after stroke. Arch Phys Med Rehabil. 2007;88(10):1314-9.

17. Kobayashi T, Leung AK, Hutchins SW. Correlations between knee extensor strength measured by a hand-held dynamometer and functional performance in patients with chronic stroke. Isokinet Exerc Sci. 2011; 19(1):33-7.

18. Knols RH, Aufdemkampe G, De Bruin ED et al. Hand-held dynamometry in patients with haematological malignancies: Measurement error in the clinical assessment of knee extension strength. BMC Musculoskelet Disord. 2009;10(1):31.

19. Clark RA, Bryant AL, Pua Y et al. Validity and reliability of the nintendo wii balance board for assessment of standing balance. Gait Posture. 2010;31(3):307-10.

20. Park DS, Lee DY, Choi SJ et al. Reliability and validity of the balancia using wii balance board for assessment of balance with stroke patients. Journal of the Korea Academia-Industrial Cooperation Society. 2013; 14(6):2767-72.

21. Lockie RG, Schultz AB, Callaghan SJ et al. The effects of isokinetic knee extensor and flexor strength on dynamic stability as measured by functional reaching. Isokinet Exerc Sci. 2013;21(4):301-9.

22. Roerdink M, Geurts AC, de Haart M et al. On the relative contribution of the paretic leg to the control of posture after stroke. Neurorehabilitation and neural repair. 2008.

23. Sousa N, Sampaio J. Effects of progressive strength training on the per- 
formance of the functional reach test and the timed get-up-and-go test in an elderly population from the rural north of portugal. Am J Hum Biol. 2005;17(6):746-51.

24. Kwon YJ, Park SJ, Jefferson J et al. The effect of open and closed kinetic chain exercises on dynamic balance ability of normal healthy adults. J Phys Ther Sci. 2013;25(6):671.

25. Jung JH, Kim JH. Correlation between bilateral reciprocal leg press test and the balance in chronic stroke patient. J Kor Phys Ther. 2013;25(4):
$180-6$.

26. Kim JH. The effects of whole body vibration exercise on balance and lower extremity muscle activity in stroke patients. J Kor Phys Ther. 2013; 25(5):266-72

27. Park SY. Assessment of isokinetic muscle strength in lower limb extensor through the ankle joint position. Daegu University Dissertation of Master's Degree. 2009. 